\title{
Explanation and the hard problem
}

\author{
Wayne Wright
}

Published online: 13 April 2007

(C) Springer Science+Business Media B.V. 2007

\section{Erratum to: Philos Stud \\ DOI 10.1007/s11098-005-2220-x}

In Wayne Wright's article 'Explanation and the Hard Problem' ' published in Philosophical Studies 132 (2), 301-330 (DOI: 10.1007/s11098-005-2220-x) the acknowledgements were unfortunately omitted. Please find them below.

Acknowledgments I am grateful to Carl Craver and Philip Robbins for many helpful comments on drafts of this paper, and for much lively discussion of the issues treated herein. Additionally, both have been gracious enough to allow me to cite work that is not yet published, for which I am thankful. Kent Johnson has been a beneficial source of questions and insights on the issues this paper tackles. David Chalmers' comments on an ancestor of this paper greatly aided my thinking about these issues.

The online version of the original article can be found at http://dx.doi.org/10.1007/s11098-005-2220-x

W. Wright $(\bowtie)$

Department of Philosophy, California State University, Long Beach, 1250 Bellflower Boulevard, MacIntosh Humanities Building 917, Long Beach, CA 90840-2408, USA

e-mail: wrightwt@mindstu.net 